\title{
FABRICATION OF PLGA/HAP AND PLGA/PHB/HAP FIBROUS NANOCOMPOSITE MATERIALS FOR OSSEOUS TISSUE REGENERATION
}

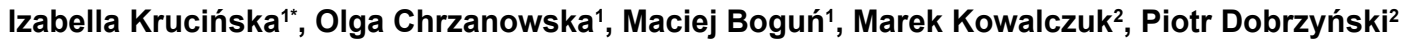

${ }^{1}$ Lodz University of Technology, Faculty of Material Technologies and Textile Design, Department of Material and Commodity Sciences and Textile Metrology, Center of Advanced Technologies of Human Friendly Textiles PRO HUMANO TEX, Lodz, Poland

${ }^{2}$ Centre of Polymer and Carbon Materials, Polish Academy of Sciences, Zabrze, Poland

e-mail: izabella.krucinska@p.lodz.pl

\begin{abstract}
:
The study presents the manufacturing of nanofibrous structures as osteoconductive, osteoinductive materials for osseous tissue regeneration. The fibrous structures were obtained by electrospinning of poly(I-lactide-coglicolide) (PLGA) with addition of hydroxyapatite (HAp) and of a blend of PLGA with polyhydroxybutyrate with HAp added. The polymers used in the experiment were synthesised by an innovative method with a zirconium catalyst. First, the optimal electrospinning process parameters were selected. For the characterisation of the obtained osseous tissue reconstruction materials, the physical, macroscopic, functional, mechanical and thermal properties as well as crystallinity index were studied. The study of the radiation sterilisation influence on average molar mass, thermal and mechanical properties was made in order to analyse the degradation effect.
\end{abstract}

\section{Keywords:}

Electrospinning, resorbable material, implant, osseous tissue regeneration, hydroxyapatite.

\section{Introduction}

Some biomaterials that are used for the regeneration of osseous tissue are well known. The biomaterials used in medical practice can be divided into two main groups, resorbable and non-resorbable materials, which are in most cases removed from the human organism after completion of the treatment process. This study focuses on resorbable materials. Among them, polymer-based materials, and especially polymers from the aliphatic polyester group, currently play an important role. The main representatives of this group include polylactide (PLA), polyglycolide (PGA) and their copolymers. PLA occurs in three optically active isomeric forms, i.e., as L-lactide, $\mathrm{D}$-lactide and L/D-lactide, as well as in an optically inactive $\mathrm{D} / \mathrm{L}$ form, which is a mixture of all three isomers [1]. In comparison with PGA, this polymer is characterised by a significantly longer resorption time, yielding lactic acid, which naturally occurs in the human organism and is eliminated as a result of metabolic processes as a degradation product. Both the above homopolymers and their copolymers have been applied in many regenerative medicine solutions [2-5]. These materials can be obtained using many methods, e.g., by classical methods such as material injection and solvent casting (for thermoactive materials) and by innovative methods such as rapid prototyping and electrospinning techniques. Another group of materials commonly used in invasive medicine are bioceramics, which are based mainly on various types of calcium phosphates, such as hydroxyapatite (HAp) [6-8]. The main advantage of these materials is that HAp is one of the most biocompatible chemical compounds and the predominant component (accounting for approximately 69\%) of total bone mass $[9,10]$. Bioceramic materials are widely applied in various types of bone repair cements, providing good bonding on the interface between an implant and natural bone [11]. Numerous studies have focused on the use of biocompatible ceramics, e.g., apatite-based ceramics, in various applications related to trauma surgeries [12-15]. However, the mechanical properties of these materials, especially brittleness, are a serious disadvantage and considerably limit the possibility of their application in the treatment of more substantial losses of osseous tissue. Thus, works concerning the development of various types of polymer-ceramic composites that combine high biocompatibility (characteristic of ceramics) with more favourable mechanical properties (originating mainly from the used polymer) have been conducted in many research centres. Because of the much simpler modelling of functionality properties compared with those of ceramics alone, the obtained composite materials can be used in the processes of regeneration of larger bone loss areas. Additionally, the fabrication of composite systems based on appropriately modified fibrous materials makes it possible to mimic almost perfectly the complex structure of the bones. The possibility of developing various forms of composites starting from MD, 1D, 2D and 3D exists with the resultant potential for obtaining appropriate relations between the mechanical strength and Young's modulus.

In addition, because of recent technological progress, it is now possible to design systems with materials based on nanotechnology to support the processes of osseous tissue regeneration. The works conducted in many research centres concerning the applications of nanotechnology in tissue engineering focus mainly on three areas: the use of appropriate nanoadditives, surface modifications and the fabrication of 
nanofibres. Various nanoadditives, such as metals and metallic compounds as well as ceramic nanoadditives, are used for tissue engineering purposes. The main representatives of metallic nanoadditives include silver, titanium dioxide and nontoxic ferromagnetics. Research concerning the materials of this group has demonstrated that silver has very good antibacterial properties, which can be used in the production of dressing materials that enhance skin regeneration $[16,17]$, whereas nano- $\mathrm{TiO}_{2}$ is used in the regeneration of osseous tissue [18]. The specific properties of ferromagnetics enable their use as drugtransporting substances within the framework of local magnetic therapy [19] or as substances helpful in the diagnostics and therapy of tumours utilising magnetic hyperthermia $[20,21]$. Another group comprises ceramic compounds based on the aforementioned resorbable ceramics, such as HAp, tricalcium phosphate, silica, montmorillonite, bioglass (Bioglass ${ }^{\circledR}$ ) and corundum ceramics. Materials of this type are used in dentistry, maxillofacial surgery and orthopaedics [22,23]. Another area of medical applications of nanotechnology consists of studies concerning nanometric surface modification, which is an important aspect in the interaction of the surfaces of implants with live cells $[24,25]$. Scientific advances have also contributed to considerable interest in nanofibres obtained by electrospinning and their medical applications. In most cases, fibrous nanostructures used for osseous tissue regeneration, obtained by electrospinning, are fabricated to develop both passive and active materials, with the latter including a system that enables the controlled release of drugs or other active biomolecules [24,26-28]. The application of nanofibres in research aiming to obtain new materials for medicine has been reflected in numerous publications $[27,29,30]$. The relevant literature includes many papers devoted to the use of nanofibres in the treatment of osseous tissue [31,32], articular cartilages [33,34], muscles [35], ligaments [36], skin [12,37] and use in cardiosurgery [9].

The aim of this paper is to present the possibility of obtaining nanofibrous structures fabricated by electrospinning from a solution of a poly(l-lactide-co-glicolide) (PLGA) with the addition of HAp and a mixture of PLGA polymers and polyhydroxybutyrate (PHB) with HAp added. The used polymer systems were synthesised according to an innovative method with a zirconium catalyst. The fabricated fibrous material was designed for use in osseous tissue regeneration as an osteoconductive, osteoinductive and biodegradable material.

\section{Materials and methods}

\subsection{Study material}

The study was performed using a fibre-forming copolymer of PLGA obtained by synthesis conducted in bulk, initiated by zirconium acetylacetonate (IV), according to the modified method described by Dobrzyński et al. [38]. The copolymer containing $84 \%$ molar lactide units, $16 \%$ molar glycolide units and less than $1 \%$ by weight unreacted L-lactide had a number average molar mass $\mathrm{Mn}=130000 \mathrm{Da}$, a glass transition temperature $\mathrm{T}_{\mathrm{g}}=54^{\circ} \mathrm{C}$, a melting temperature $\mathrm{T}_{\mathrm{m}}=155^{\circ} \mathrm{C}$ and a melting heat $\mathrm{dH}=45 \mathrm{~J} / \mathrm{g}$. The copolymer was characterised by a special segmental microstructure of the chain containing both long lactide and glycolide segments and short, alternating, elastic glycolide and lactide sequences. The second variant was a polymer mixture containing the glycolide and L-lactide copolymer as well as atactic poly(3-hydroxybutyrate) - $\mathrm{PBH}$ obtained by the anionic polymerisation of cyclic ß-butyrolactone in the presence of t-butyl ammonium acetate [39]. The blend of PLGA with $\mathrm{PBH}$ (PLGA/PHB) was prepared in a mixing extruder at $145-160^{\circ} \mathrm{C}$ and was characterised by a vitrification temperature $\mathrm{T}_{\mathrm{g}}=45^{\circ} \mathrm{C}$, a melting temperature $\mathrm{T}_{\mathrm{m}}=152^{\circ} \mathrm{C}$ and a melting heat $\mathrm{dH}=35 \mathrm{~J} / \mathrm{g}$. The mixture contains $90 \%$ PLGA copolymer, obtained as described above, with $84 \%$ molar lactide content and a number average molar mass of $\mathrm{Mn}=120000 \mathrm{Da}$, and it has $10 \%$ atactic PHB, obtained by the anionic polymerisation of cyclic ß-butyrolactone in the presence of t-butyl ammonium acetate, with a number average molar mass $\mathrm{Mn}=60000 \mathrm{Da}$. Gel permeation chromatography (GPC) analysis of both the copolymer and the mixture demonstrated a unimodal distribution of molar masses.

Both the PLGA copolymer and the PLGA/PHB blend used in the study contain a semicrystalline phase associated with the thermal history of the samples (slow cooling from the reaction temperature to the room temperature). However, after melting and rapid cooling (occurring in the granulation process), crystallisation was inhibited, which explains why the granulate samples are amorphous in character.

To characterise the thermal properties of the polymer granulate used in the experiment, the material was investigated with differential scanning calorimetry (DSC) using a Q2000 TA Instrument Inc. calorimeter. The heat was increased stepwise at a $10^{\circ} \mathrm{C} / \mathrm{min}$ rate. The material was cyclically heated from -50 to $200^{\circ} \mathrm{C}$, then cooled back to $-50^{\circ} \mathrm{C}$ and heated at a constant rate to $200^{\circ} \mathrm{C}$. The results are presented in table 1.

Table 1. DSC results of thermal analysis for the used granulates obtained during the first heating cycle

\begin{tabular}{|c|c|c|}
\hline $\begin{array}{c}\text { Raw } \\
\text { materials }\end{array}$ & $\begin{array}{c}\text { Glass transition } \\
\text { temperature, } \\
\mathbf{T}_{\mathbf{g}^{\circ}}{ }^{\circ} \mathbf{C}\end{array}$ & $\begin{array}{c}\text { Melt temperature, } \\
\mathbf{T}_{\mathbf{m}},{ }^{\circ} \mathbf{C}\end{array}$ \\
\hline PLGA & 54 & Amorphous \\
\hline PLGA/PHB & 53 & Amorphous \\
\hline
\end{tabular}

DSC, differential scanning calorimetry; PHB, polyhydroxybutyrate; PLGA, poly(I-lactide-co-glicolide).

To endow the fibres with osteoinductive properties, HAp powder with a grain size below $200 \mathrm{~nm}$, purchased from Sigma Aldrich, was added to the polymer solution.

\subsection{Method of obtaining and characterising the spinning solutions used in the electrospinning process}

The preliminary experiments aiming to obtain the polymer solution were performed using dichloromethane. However, the solvent proved too volatile for fibre formation from the experimental polymers described above. Therefore, further experiments were conducted using dimethyl sulphoxide (DMSO), which is approved for medical applications. 
Four solutions of PLGA in DMSO with polymer concentrations of $4,6,10$ and 15 wt. $\%$ were prepared. Four corresponding solutions with the same PLGA concentrations in DMSO, with 1 wt.\% (as related to the polymer) HAp added (PLGA/1\% HAp), were also obtained. Accordingly, HAp was mixed with DMSO using a sonic stirrer for 20 minutes; then, the polymer was added to the HAp solution in DMSO and mixed with a magnetic stirrer. Preliminary electrospinning trials demonstrated the applicability for further experiments only of the solutions with $6 \%, 10 \%$ and $15 \%$ polymer concentrations. The $4 \%$ polymer concentration proved too low to enable the formation of a substrate consisting of homogeneous fibres. Therefore, further experiments were conducted using the $6 \%, 10 \%$ and $15 \%$ solutions, whose rheological properties were determined with a rotation rheometer (manufactured by Anton Paar). The results are presented in table 2 .

Preliminary experiments utilising the PLGA/PHB mixture demonstrated that it is possible to form fibres from solutions whose concentrations exceed $10 \%$. Therefore, the spinning condition optimisation process was conducted for the $15 \%$, $20 \%$ and $25 \%$ solutions. The results concerning the rheological properties obtained for these solutions are listed in table 3.

\subsection{Fibrous substrate formation method}

The fibrous substrate was formed by electrospinning using a multicapillary experimental stand described by Krucińska et al. [40]. The experiments were conducted using capillaries of $0.9 \mathrm{~mm}$ diameter with a drum collector rotation speed of $20 \mathrm{rpm}$ in the first series of measurements, with variable distances between the capillaries and the collector and variable voltages applied to the upper electrode.

\subsection{Methodology applied for characterisation of the properties of the obtained osseous tissue reconstruction materials}

First, the physical properties characterising the macroscopic structure of the obtained materials for osseous tissue repair were investigated. Subsequently, the obtained materials were subjected to investigations aiming to characterise the microstructure of the obtained materials and remodelling of that microstructure due to the radiation sterilisation process. The sterilisation process was conducted using a gamma irradiation dose of 28 kGy.

\subsection{Methodology applied for characterisation of macroscopic and functional properties of the obtained materials}

The transverse dimensions of the formed fibres were assessed using Lucia G software, which is designed for the analysis of images obtained from a Nova Nano SEM electron microscope manufactured by FEl. Approximately 200 fibres were analysed for each variant to calculate the transverse dimension values. The diameter values and their dispersion were determined based on the investigations. The surface mass and thickness of the analysed fleeces were appropriately assessed according to the ISO standard $[41,42]$ ("Methods of test for nonwovens.

Table 2. Rheological characteristics of PLGA and PLGA/1\% HAp solutions used in the electrospinning process.

\begin{tabular}{|c|c|c|c|}
\hline Polymer & $\begin{array}{c}\text { Concentration of spinning } \\
\text { solution, \% wt }\end{array}$ & Rheological parameter, $\mathbf{n}$ & Rheological parameter, $\mathbf{k}$ \\
\hline PLGA & 6 & 0.0001 & 2.679 \\
\hline PLGA & 10 & 0.0780 & 1.302 \\
\hline PLGA & 15 & 1.4220 & 1.196 \\
\hline PLGA/1\% HAp & 6 & 0.1070 & 1.107 \\
\hline PLGA/1\% HAp & 10 & 0.2110 & 1.276 \\
\hline PLGA/1\% HAp & 15 & 1.8660 & 1.223 \\
\hline
\end{tabular}

HAp, hydroxyapatite; PLGA, poly(l-lactide-co-glicolide).

Table 3. Rheological characteristics of PLGA/PHB and PLGA/PHB blend with $1 \%$ HAp (PLGA/PHB/1\% HAp) solutions used in the electrospinning process.

\begin{tabular}{|c|c|c|c|}
\hline Polymer & $\begin{array}{c}\text { Concentration of spinning } \\
\text { solution, \% wt }\end{array}$ & Rheological parameter, $\mathbf{n}$ & Rheological parameter, $\mathbf{k}$ \\
\hline PLGA/PHB & 15 & 0.0450 & 1.376 \\
\hline PLGA/PHB & 20 & 0.5030 & 1.169 \\
\hline PLGA/PHB & 25 & 12.9800 & 0.932 \\
\hline PLGA/PHB/1\% HAp & 15 & 0.1830 & 1.216 \\
\hline PLGA/PHB/1\% HAp & 20 & 0.4930 & 1.431 \\
\hline
\end{tabular}

HAp, hydroxyapatite; PHB, polyhydroxybutyrate; PLGA, poly(l-lactide-co-glicolide). 
Determination of mass per unit area") and ISO 9073-2:1995 ("Methods of test for nonwovens. Determination of thickness").

Measurements of the porosity were performed using an AUTOPORE IV, 9520 apparatus. In all the experiments, a penetrometer with a $5 \mathrm{ml}$ cup volume and 0.39 of stem was used. In the first step, all the samples were degased with a controlled speed of evacuation. The minimal value of pressure was $20 \mathrm{mmHg}$. The measurements were performed for pressures of mercury ranging from $0.016 \mathrm{MPa}$ to $414 \mathrm{MPa}$, which enabled analysis of pores ranging in size from 3.5 to $400000 \mathrm{~nm}$.

The functional properties of the formed fleeces were tested according to the following standards. Airpermeability was assessed in ISO standard [43] ("Textiles. Test methods for nonwovens. Determination of air permeability"). The sorption capacity was assessed with a Sorb 3 absorptiometer, enabling the recording of the dynamics of water (physiological saline) absorption in time. The maximal amount of the absorbed liquid related to the mass of the investigated sample provides the basis for assessment of the sorption capacity of the investigated material. The mechanical properties were tested using a unidirectional extension test according to EN ISO 29073-3:1992 test [44] ("Methods of test for nonwovens. Determination of tensile strength and elongation"). The mechanical properties tests were conducted for the nonwoven samples before and after sterilisation.

2.6. Methodology applied for characterisation of thermal properties and supramolecular structure of the obtained materials

First, the thermal properties of the fibres formed by electrospinning before and after sterilisation were investigated using the DSC method. The tests were conducted according to the methodology described in section 2 of Nanonics MultiView 1000. The supermolecular structures of the investigated nonwoven fabric were analysed using the wide-angle X-ray scattering (WAXS) method. The diffraction profiles were obtained with $\mathrm{Cu} \mathrm{Ka}(\lambda=0.154 \mathrm{~nm})$ using an X'Pert Pro X-ray diffractometer (from PANalytical) operating at $30 \mathrm{kV}$ and 30 $\mathrm{mA}$. The samples were studied in powder form.

Then, comparative analysis of the average molar mass was performed using the GPC and nuclear magnetic resonance $\left({ }^{1} \mathrm{H}\right.$ NMR) techniques. The number average molar mass $(\mathrm{Mn})$ of the samples was determined with GPC using a chromatograph equipped with a separation system consisting of two styragel PLgel $5 \mu \mathrm{m}$ Mixed-C type high resolution columns (Polymer Laboratories) working under thermostated conditions at $35^{\circ} \mathrm{C}$. Chloroform with a $1 \mathrm{ml} / \mathrm{min}$ flow rate, obtained using a Spectra-Physics 8800 pump, was used as the mobile phase. The detection system consisted of a Shodex SE 61 differential refractometer. The calibration curves were obtained using low-dispersion polystyrene standards. The NMR spectra were recorded with a Varian VXR-300 spectrometer. The ${ }^{1} \mathrm{H}$ NMR spectra were obtained in $\mathrm{CDCl} 3$ using tetramethylsilane as the internal standard. The proton spectra were recorded at $28^{\circ} \mathrm{C}$ from 64 scans, with a 3.74-s acquisition time and a $7-\mu$ s impulse width. The composition of the copolymers was calculated based on integration of the glycolide $(\delta=4.6-4.9 \mathrm{ppm})$ and lactide ( $w \delta=5.1-5.3$ ) units' proton signals. The composition of the blend was estimated based on integrations of the copolymer and PHB proton signals.

\subsection{Statistics}

The normality of the distribution of the mechanical properties was verified using the Shapiro-Wilk test with an adopted significance level $\alpha$ equal to 0.05 . The null hypothesis was that the empirical distribution is Gauss distribution. According to the alternative hypothesis, the distribution of the mechanical properties was not normal. Because of verification, the zero hypothesis had to be rejected.

Further analyses utilised the Kruskal-Wallis test with the adopted significance level $\alpha$ equal to 0.05 . The zero hypothesis assumed that the mean values originated from the same population and consequently did not differ significantly, whereas the alternative hypothesis assumed significant differences of the mean values. The zero hypothesis was rejected.

Tukey's test was selected for verification of the mean values of the mechanical parameters determined before and after sterilisation for samples electrospun from PLGA with 1\% HAp in DMSO and for samples electrospun from PLGA/PHB with $1 \%$ HAp in DMSO. According to the zero hypothesis, the mean values of the mechanical parameters determined for the material samples before and after sterilisation did not differ significantly. The alternative hypothesis assumed that there were significant differences between their mean values.

The error of the mean value was calculated according to the nomenclature [45].

\section{Results}

\subsection{Results of determination of the effect of the electrospinning process parameters on the transverse dimensions of the formed fibres}

In the first part of the study, electrospinning from 6\% PLGA solution in DMSO was performed. During the process, a constant distance of $25 \mathrm{~cm}$ was maintained between the drum collector and the capillaries, whereas the voltage applied to the upper electrode was increased. The voltage values amounted to 15,20 and $30 \mathrm{kV}$ in the respective trials. The $25 \mathrm{~cm}$ distance between the electrodes was selected because the DMSO used to obtain the spinning solution is a solvent that evaporates slowly at room temperature. A greater distance between the drum collector and the capillaries might increase the fibre deposition time on the drum and result in evaporation of some of the solvent. Then, the obtained nonwovens were assessed with respect to the transverse dimensions of the fibres. The mean values of the fibre transverse dimensions and their distributions for the specific variants with photos of example SEM images are presented in figure 1. 


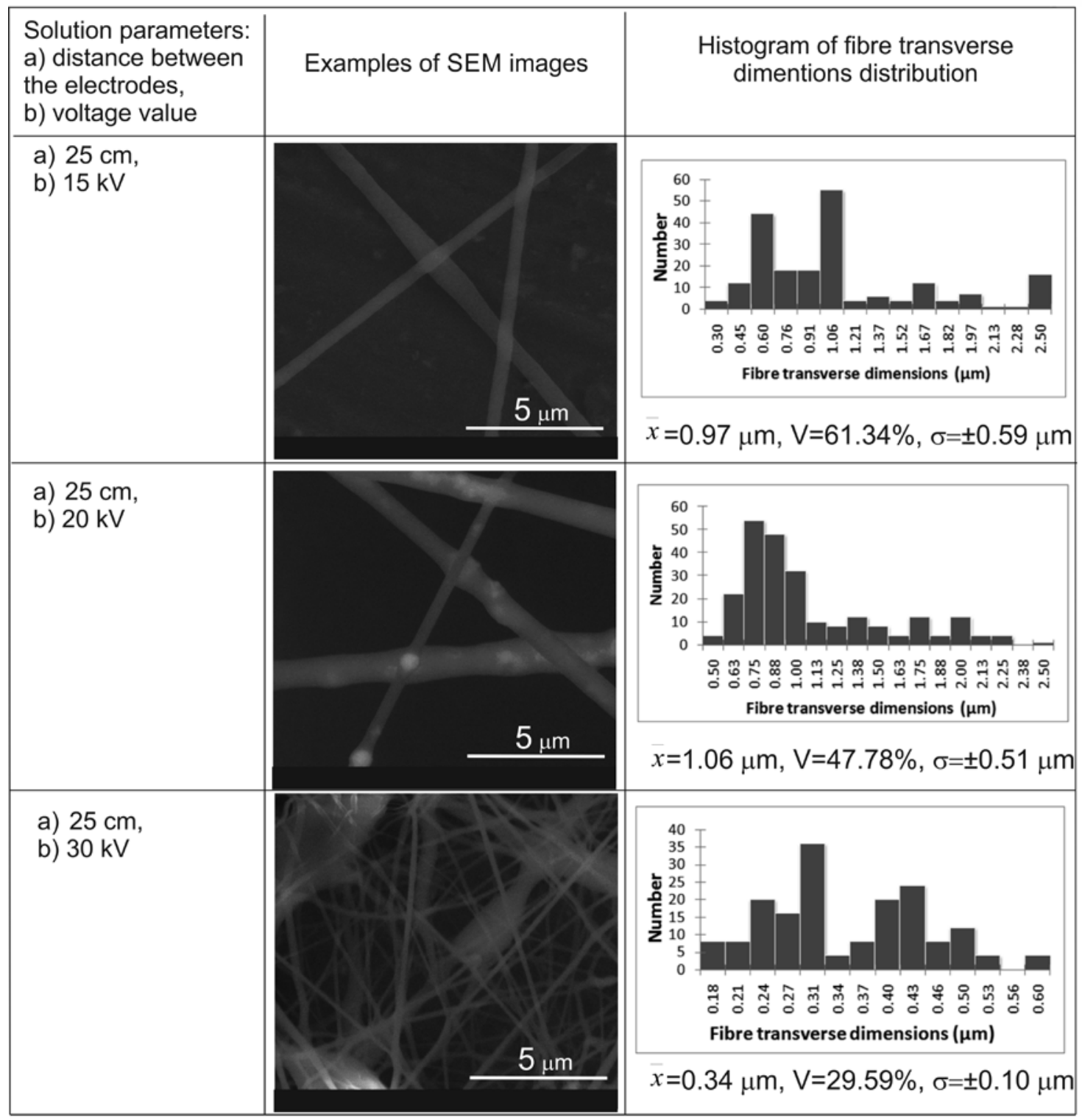

Figure 1. Mean values of fibre transverse dimensions and SEM images obtained by electrospinning from 6\% poly(I-lactide-co-glicolide) (PLGA) solution in dimethyl sulphoxide (DMSO) with a constant distance between the electrodes

The results presented in figure 1 indicate that the fabrication of fleece with fibre transverse dimensions of a few hundred nanometres magnitude was possible only when the distance between the collector drum and the capillaries was equal to 25 $\mathrm{cm}$, with a $30 \mathrm{kV}$ voltage applied to the upper electrode. The application of 15 and $25 \mathrm{kV}$ voltages resulted in the formation of fleece with fibre transverse dimensions of approximately 1 $\mu \mathrm{m}$. Thus, it can be concluded that $30 \mathrm{kV}$ was the appropriate voltage value for obtaining nanofibres by electrospinning from $6 \%$ PLGA solution in DMSO.

The following stage of the experiment involved continuation of the selection of the optimal distance between the electrodes. Trials were conducted for 15 and $35 \mathrm{~cm}$ distances between the upper and lower electrodes, maintaining a constant voltage of $30 \mathrm{kV}$. Similar to the first stage, the transverse dimensions of fibres of the obtained fleeces were measured. The fibre transverse dimension results are presented in figure 2 . The fleeces were characterised by $0.29 \pm 0.007$ and $0.09 \pm 0.005$ $\mu \mathrm{m}$ transverse dimensions. At that stage of the experiment, it was impossible to obtain more homogeneous fibrous substrates; only a reduction of the transverse fibre dimension from $1.06 \mu \mathrm{m}$, with a standard deviation of $0.51 \mu \mathrm{m}$, to 0.09 $\mu \mathrm{m}$, with a standard deviation of $0.08 \mu \mathrm{m}$, was achieved. The lowest variance coefficient, $29.6 \%$, was obtained for the sample fabricated under the following conditions: a $25 \mathrm{~cm}$ distance between the upper and the lower electrodes, a $30 \mathrm{kV}$ voltage, a $20 \mathrm{rpm}$ rotation speed of the drum collector and a $20 \mathrm{~mm} / \mathrm{s}$ needle bar speed. Despite the application of various technological parameters of the electrospinning process, a nonwoven material with more homogeneous fibres could not be obtained.

Another series of experiments was conducted to improve the homogeneity of the transverse dimensions in the fleece. For this purpose, $10 \%$ and $15 \%$ PLGA solutions in DMSO were electrospun. The electrospinning process was conducted with the optimal technological parameters for the 6\% PLGA solution in DMSO: a $25 \mathrm{~cm}$ distance between the electrodes and a $30 \mathrm{kV}$ voltage. Figure 3 presents the correlation between the 


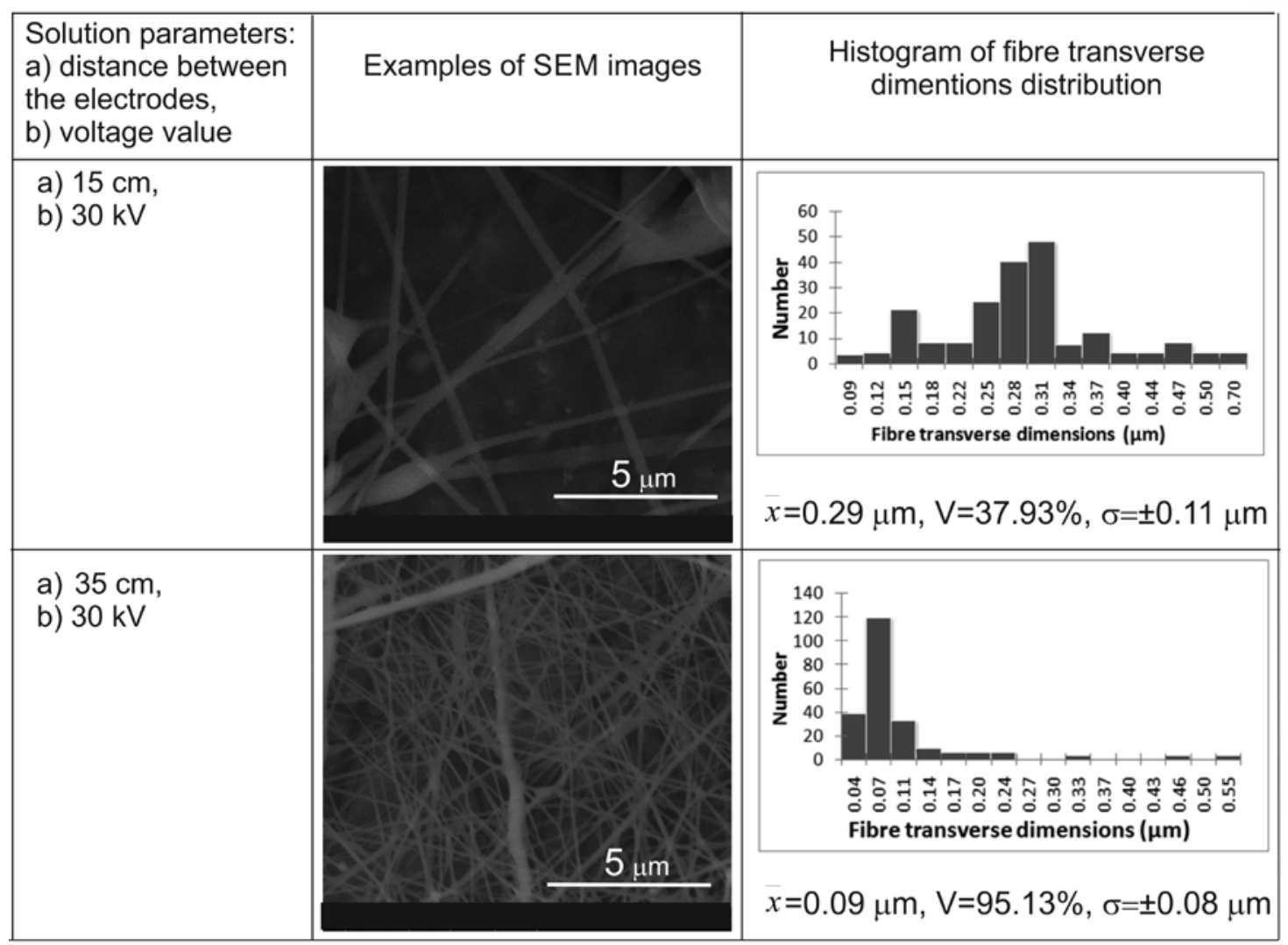

Figure 2. Mean values of fibre transverse dimensions and SEM images obtained by electrospinning from 6\% poly(I-lactide-co-glicolide) (PLGA) solution in dimethyl sulphoxide (DMSO) with a constant voltage applied

\begin{tabular}{|c|c|c|}
\hline $\begin{array}{l}\text { Solution parameters: } \\
\text { a) polymer } \\
\text { concentration, } \\
\text { b) hydroxyapatite } \\
\text { content }\end{array}$ & Examples of SEM images & $\begin{array}{l}\text { Histogram of fibre transverse } \\
\text { dimentions distribution }\end{array}$ \\
\hline $\begin{array}{l}\text { a) } 10 \% \text {, } \\
\text { b) without } \\
\text { hydroxyapatite } \\
\text { content }\end{array}$ & & 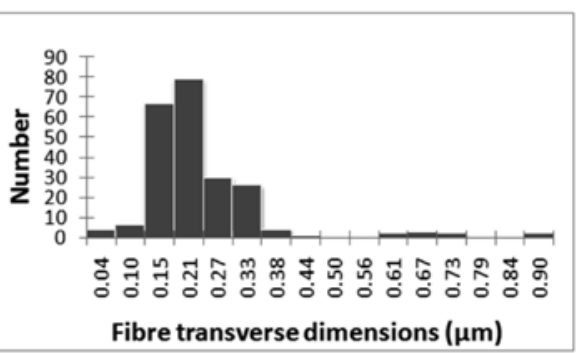 \\
\hline & & $x=0.21 \mu \mathrm{m}, \mathrm{V}=81.09 \%, \sigma= \pm 0.17 \mu \mathrm{m}$ \\
\hline $\begin{array}{l}\text { a) } 15 \% \text {, } \\
\text { b) without } \\
\text { hydroxyapatite } \\
\text { content }\end{array}$ & & 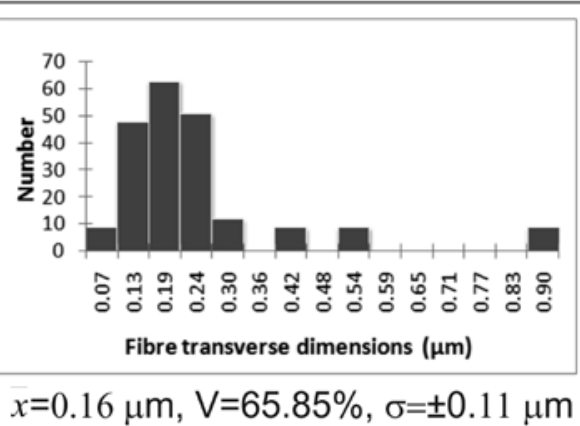 \\
\hline
\end{tabular}

Figure 3. Mean values of fibre transverse dimensions and SEM images obtained by electrospinning from $10 \%$ and $15 \%$ poly(I-lactide-co-glicolide) (PLGA) solutions in dimethyl sulphoxide (DMSO) 
transverse fibre dimensions and the PLGA concentration in the solution.

The experiments indicated that an increased PLGA concentration in the solution resulted in a decrease of the mean transverse fibre dimensions. The mean transverse fibre dimensions for the $6 \%$ and $15 \%$ PLGA solutions in DMSO were $0.34 \pm 0.007 \mu \mathrm{m}$ and $0.16 \pm 0.007 \mu \mathrm{m}$, respectively. However, as the PLGA concentration in the spinning solution increased, the homogeneity of the transverse fibre dimensions in the nonwoven deteriorated. The variation coefficient increased from $29.59 \%$ (for the 6\% PLGA solution in DMSO) to $65.85 \%$ (for the 15\% PLGA solution in DMSO).

The $6 \%$ concentration was selected as the optimal parameter for the PLGA solution in DMSO with respect to the mean transverse fibre dimensions and their dispersion. The $30 \mathrm{kV}$ voltage and $25 \mathrm{~cm}$ distance between the drum collector and the capillaries were selected as the optimal electrospinning parameters to obtain the most desirable fibre transverse dimensions. The subsequent stage of the experiment involved conducting the electrospinning process from $6 \%, 10 \%$ and $15 \%$ PLGA solutions in DMSO with 1 wt.\% HAp added. The same electrospinning parameters as those considered optimal for HAp-free PLGA solution in DMSO (30 kV voltage and $25 \mathrm{~cm}$ distance between the upper and lower electrodes) were applied in the process. The transverse dimension results and sample SEM images are presented in figure 4.

The transverse dimensions of the fibres obtained from the $10 \%$ and $15 \%$ PLGAsolutions in DMSO with $1 \%$ HAp added increased by approximately $60 \%$ compared with the dimensions of the fibres electrospun from PLGA solutions without the addition of HAp. In contrast, the diameter value for the $6 \%$ solution decreased by approximately $17 \%$. Increased homogeneity of the transverse diameters of fibres obtained from PLGA solutions with 1\% HAp compared with those obtained from PLGA solutions containing no HAp was also observed. For the experiments with HAp added, the highest variation coefficient value of $50.79 \%$ was obtained for the $6 \%$ PLGA solution in

\begin{tabular}{|c|c|c|}
\hline $\begin{array}{l}\text { Solution parameters: } \\
\text { a) polymer } \\
\text { concentration, } \\
\text { b) hydroxyapatite } \\
\text { content }\end{array}$ & Examples of SEM images & $\begin{array}{l}\text { Histogram of fibre transverse } \\
\text { dimentions distribution }\end{array}$ \\
\hline $\begin{array}{l}\text { a) } 6 \% \\
\text { b) with } \\
\text { hydroxyapatite } \\
\text { content }\end{array}$ & & 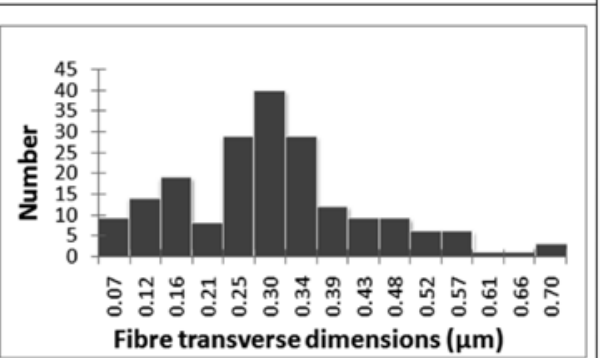 \\
\hline & & $\bar{x}=0.28 \mu \mathrm{m}, \mathrm{V}=50.79 \%, \sigma= \pm 0.14 \mu \mathrm{m}$ \\
\hline $\begin{array}{l}\text { a) } 10 \% \text {, } \\
\text { b) with } \\
\text { hydroxyapatite } \\
\text { content }\end{array}$ & & 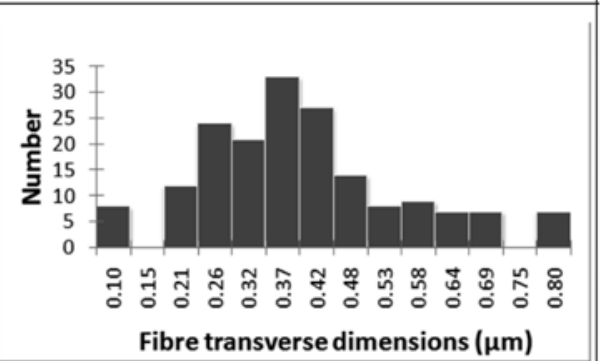 \\
\hline & & $\bar{x}=0.33 \mu \mathrm{m}, \mathrm{V}=46.03 \%, \sigma= \pm 0.15 \mu \mathrm{m}$ \\
\hline $\begin{array}{l}\text { a) } 15 \% \text {, } \\
\text { b) with } \\
\text { hydroxyapatite } \\
\text { content }\end{array}$ & & 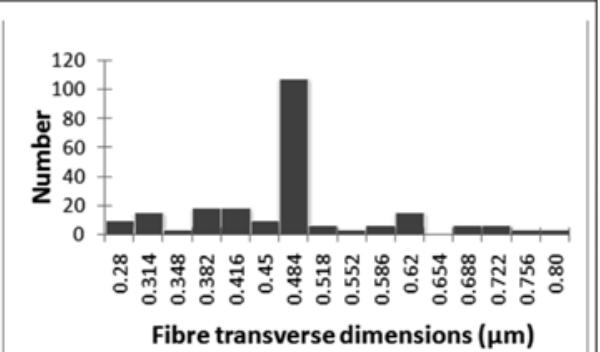 \\
\hline
\end{tabular}

Figure 4. Mean values of fibre transverse dimensions and SEM images obtained by electrospinning from $6 \%, 10 \%$ and $15 \%$ poly(I-lactide-coglicolide) (PLGA) solutions in dimethyl sulphoxide (DMSO) with $1 \%$ HAp content 
DMSO, whereas the lowest, $22.17 \%$, was obtained for the $15 \%$ PLGA solution in DMSO. Thus, a correlation opposite to that for the fibrous substrate fabricated without the nanoadditive was observed. The parameters that were determined to be optimal for the fabrication of nonwovens of this type included the $15 \%$ concentration of the spinning solution with $1 \%$ HAp addition, the $30 \mathrm{kV}$ voltage applied between the electrodes and the $25 \mathrm{~cm}$ distance between the electrodes.

The next cycle of experiments involved electrospinning from a PLGA/PHB polymer mixture in DMSO and analysis of the effect of the addition of $1 \%$ HAp on the transverse dimensions of the obtained fibres. The process was conducted with the concentrations that were previously determined to be optimal for the PLGA/PHB system without the nanoadditive and under the optimal conditions for electrospinning. The fibres were electrospun from $15 \%, 20 \%$ and $25 \%$ PLGA/PHB solutions in DMSO, with a $30 \mathrm{kV}$ voltage and a $25 \mathrm{~cm}$ distance between the drum collector and the capillaries. The use of concentrations of spinning solutions that were higher than those used for electrospinning from PLGA in DMSO was associated with the obtained fibres failing to solidify for lower concentrations of PLGA/PHB in DMSO; the fibres tended to merge and form a film instead of a fibrous substrate. The transverse fibre dimension results and sample SEM images are presented in figure 5.

The transverse dimensions of the obtained fibres from all of the PLGA/PHB solutions in DMSO amounted to a few hundred nanometres. The smallest mean transverse dimension, $0.15 \pm 0.004 \mu \mathrm{m}$, was obtained for the $20 \%$ PLGA/PHB solution in DMSO, and the largest one, $0.31 \pm$ $0.01 \mu \mathrm{m}$, was obtained for the $25 \%$ solution. Increasing the polymer concentration in the spinning solution resulted in deterioration of the homogeneity of the mean transverse dimensions. The lowest variation coefficient $(27.77 \%)$ was obtained for the 15\% PLGA/PHB concentration in DMSO, whereas the highest one (64.05\%) was obtained for the $25 \%$ PLGA/PHB concentration in DMSO.

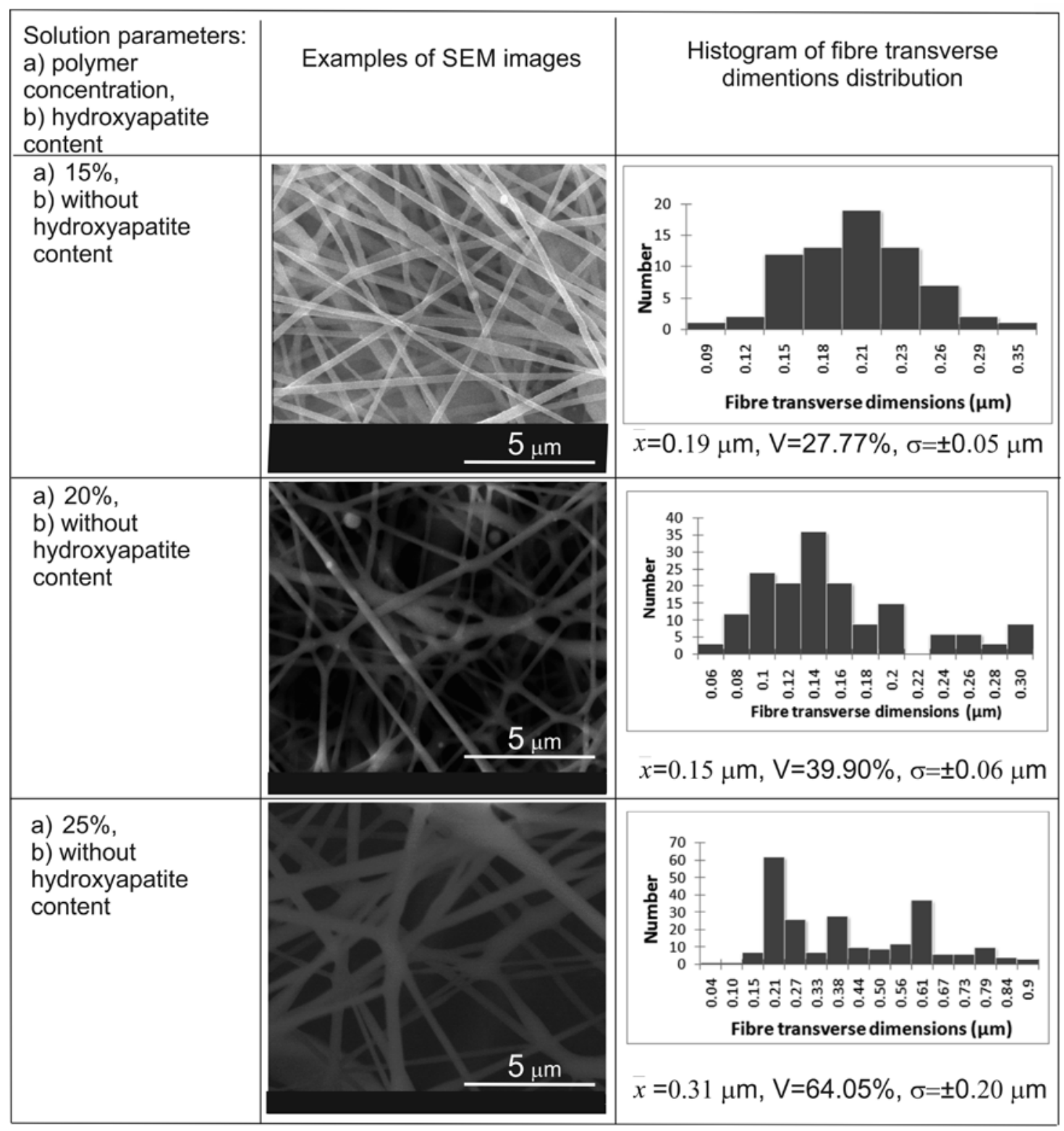

Figure 5. Mean values of fibre transverse dimensions and SEM images obtained by electrospinning from $15 \%$, $20 \%$ and $25 \%$ poly(I-lactide-coglicolide) (PLGA)/polyhydroxybutyrate (PHB) solutions in dimethyl sulphoxide (DMSO) without hydroxyapatite (HAp) content 
For the PLGA/PHB system with or without the addition of HAp, increasing the polymer concentration resulted in an increase of the mean transverse dimension of the obtained fibres. The transverse dimension results for the nonwovens obtained from the $15 \%, 20 \%$ and $25 \%$ PLGA/PHB solutions with $1 \%$ HAp and their sample SEM images are presented in figure 6.

The lowest mean fibre dimension value, $0.18 \pm 0.003 \mu \mathrm{m}$, was obtained for the 15\% PLGA/PHB solution in DMSO with $1 \%$ $\mathrm{HAp}$, and the highest, $0.35 \pm 0.009 \mu \mathrm{m}$, was obtained for the $25 \%$ PLGA/PHB solution with 1\% HAp added. Similar to the results for electrospinning from pure PLGA/PHB, the lowest variation coefficient (25.56\%) was obtained for the 15\% PLGA/ PHB solution in DMSO with 1\% HAp addition. Based on the obtained results, the $15 \%$ concentration was determined to be optimal for the PLGA/PHB solution in DMSO with 1\% HAp in combination with the electrospinning parameters of a $30 \mathrm{kV}$ voltage and a $25 \mathrm{~cm}$ distance between the drum collector and the capillaries.

\subsection{Results of tests of macroscopic and functional properties of the obtained materials for osseous tissue regeneration}

The macroscopic and functional properties of the nonwovens, fabricated under optimal conditions to serve as biomaterials for osseous tissue regeneration, were tested according to the methodology specified in Section 2 point 5 . The results obtained for the samples before sterilisation are presented in tables 4 and 5. Table 6 specifies the mechanical properties of the nonwoven samples before and after the sterilisation process.

\subsection{Results of tests of thermal properties of the obtained materials for osseous tissue regeneration}

The material of the fibres obtained by electrospinning was characterised using the methodology presented in Section 2 , point 6 . The obtained thermograms of the changes in

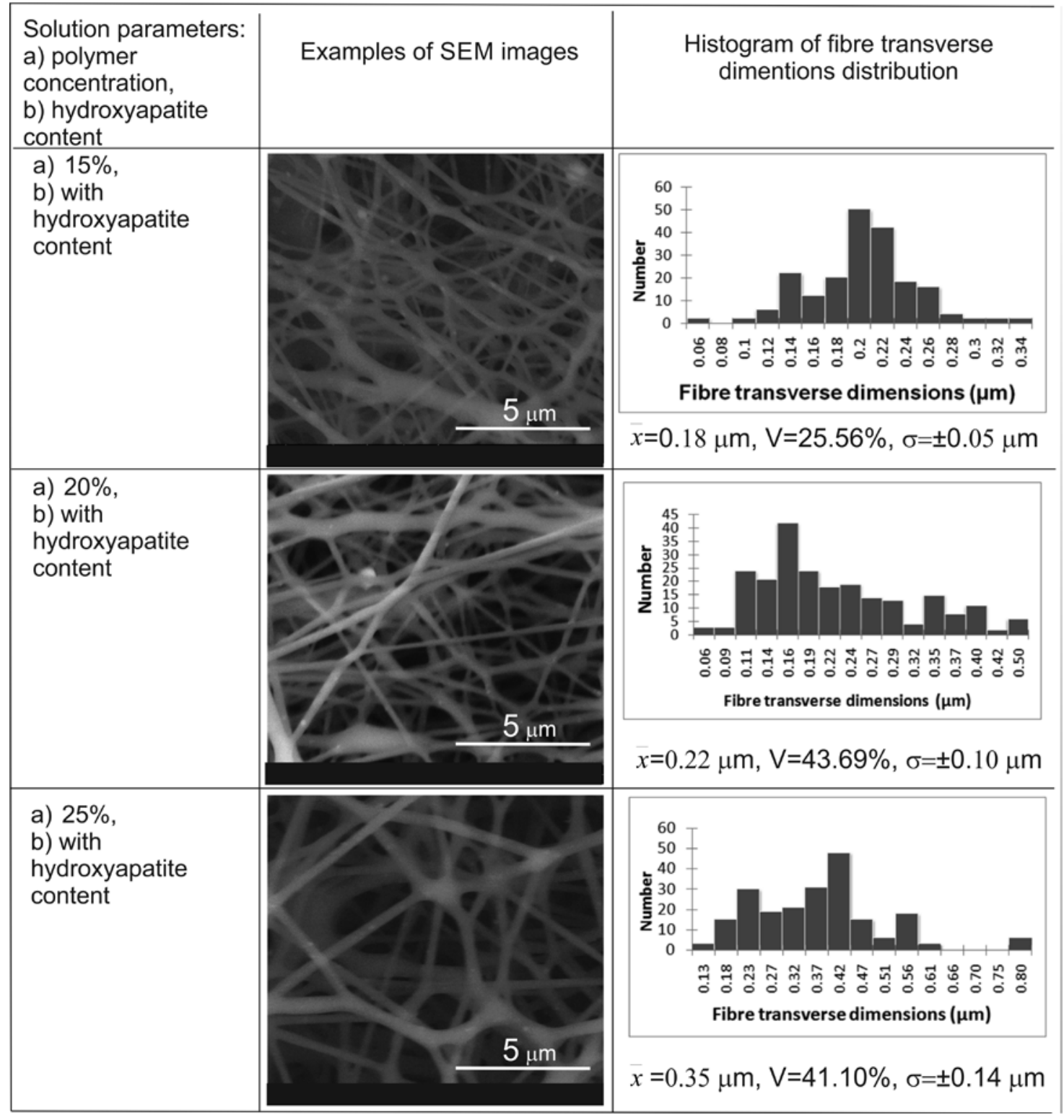

Figure 6. Mean values of fibre transverse dimensions and SEM images obtained by electrospinning from $15 \%, 20 \%$ and $25 \%$ poly(l-lactide-coglicolide) (PLGA)/polyhydroxybutyrate (PHB) solutions in dimethyl sulphoxide (DMSO) with $1 \%$ hydroxyapatite (HAp) content 
Table 4. Macroscopic properties of nonwovens fabricated under optimal conditions.

\begin{tabular}{|c|c|c|c|c|c|}
\hline Polymer & $\begin{array}{c}\text { Average fibres } \\
\text { diameter }(\boldsymbol{\mu} \mathbf{m})\end{array}$ & $\begin{array}{c}\text { Surface mass } \\
\left(\mathbf{g} / \mathbf{m}^{\mathbf{2}}\right)\end{array}$ & $\begin{array}{c}\text { Thickness } \\
(\mathbf{m m})\end{array}$ & $\begin{array}{c}\text { Total area of } \\
\text { pores }\left(\mathbf{m}^{\mathbf{2}} \mathbf{g}\right)\end{array}$ & $\begin{array}{c}\text { Average pore size } \\
(\boldsymbol{\mu m})\end{array}$ \\
\hline PLGA/1\% HAp & $0.46 \pm 0.007$ & 4.50 & 0.03 & 1.55 & 105.6 \\
\hline PLGA/PHB/1\% HAp & $0.18 \pm 0.003$ & 20.40 & 0.07 & 2.34 & 4.28 \\
\hline
\end{tabular}

HAp, hydroxyapatite; PHB, polyhydroxybutyrate; PLGA, poly(I-lactide-co-glicolide).

Table 5. Functional properties of nonwovens fabricated under optimal conditions.

\begin{tabular}{|c|c|c|}
\hline Polymer & Air permeability $\left(\mathbf{I} / \mathbf{m}^{2 *} \mathbf{s}\right)$ & Sorption capacity $\left(\mathbf{g} / \mathbf{g}_{\text {sample }}\right)$ \\
\hline PLGA/1\% HAp & 25 & 8.22 \\
\hline PLGA/PHB/1\% HAp & 3 & 15.64 \\
\hline
\end{tabular}

HAp, hydroxyapatite; PHB, polyhydroxybutyrate; PLGA, poly(I-lactide-co-glicolide).

Table 6. Mechanical properties of nonwovens before and after the sterilisation process

\begin{tabular}{|c|c|c|c|c|}
\hline & $\begin{array}{c}\text { PLGA/1\% HAp } \\
\text { before sterilisation }\end{array}$ & $\begin{array}{l}\text { PLGA/1\% HAp } \\
\text { after sterilisation }\end{array}$ & $\begin{array}{l}\text { PLGA/PHB } / 1 \% \text { HAp } \\
\text { before sterilisation }\end{array}$ & $\begin{array}{l}\text { PLGA/PHB/1\% HAp } \\
\text { after sterilisation }\end{array}$ \\
\hline $\begin{array}{l}\text { Stress at break (along) } \\
(\mathrm{MPa})\end{array}$ & $4.13 \pm 0.11$ & $3.55 \pm 0.26$ & $5.09 \pm 0.14$ & $4.22 \pm 0.17$ \\
\hline Statistical analysis & \multicolumn{2}{|c|}{$\begin{array}{l}\text { statistically significant differences, Tukey's test, } \\
\qquad P<0.05\end{array}$} & \multicolumn{2}{|c|}{$\begin{array}{l}\text { statistically significant differences, Tukey's test, } \\
\qquad P<0.05\end{array}$} \\
\hline $\begin{array}{l}\text { Stress at break } \\
\text { (across) (MPa) }\end{array}$ & $5.25 \pm 0.24$ & $4.03 \pm 0.21$ & $5.38 \pm 0.14$ & $4.68 \pm 0.08$ \\
\hline Statistical analysis & \multicolumn{2}{|c|}{$\begin{array}{l}\text { statistically significant differences, Tukey's test, } \\
\qquad P<0.05\end{array}$} & \multicolumn{2}{|c|}{$\begin{array}{l}\text { statistically significant differences, Tukey's test, } \\
\qquad P<0.05\end{array}$} \\
\hline $\begin{array}{l}\text { Strain at break (along) } \\
(\%)\end{array}$ & $37.27 \pm 2.66$ & $23.06 \pm 1.52$ & $6.26 \pm 0.85$ & $4.21 \pm 0.39$ \\
\hline Statistical analysis & \multicolumn{2}{|c|}{$\begin{array}{l}\text { statistically significant differences, Tukey's test, } \\
\qquad P<0.05\end{array}$} & \multicolumn{2}{|c|}{$\begin{array}{l}\text { statistically significant differences, Tukey's test, } \\
\qquad P<0.05\end{array}$} \\
\hline $\begin{array}{l}\text { Strain at break } \\
\text { (across) }(\%)\end{array}$ & $52.46 \pm 2.24$ & $23.34 \pm 1.04$ & $5.47 \pm 0.72$ & $3.72 \pm 0.28$ \\
\hline Statistical analysis & \multicolumn{2}{|c|}{$\begin{array}{l}\text { statistically significant differences, Tukey's test, } \\
\qquad P<0.05\end{array}$} & \multicolumn{2}{|c|}{$\begin{array}{l}\text { statistically significant differences, Tukey's test, } \\
\qquad P<0.05\end{array}$} \\
\hline
\end{tabular}

HAp, hydroxyapatite; PHB, polyhydroxybutyrate; PLGA, poly(I-lactide-co-glicolide).

heat flow through the materials, illustrating the changes that occurred in the fibre material, are presented in figures 7 and 8.

The DSC curves obtained for the fibres before and after sterilisation are compared with the curves obtained for the polymer granulates.

To analyse the supramolecular structure of native granulates (PLGA, PLGA/PHB) and of PLGA/1\% HAp and PLGA/PHB/1\% HAp, samples fabricated under optimal conditions were studied by using WAXS. According to the Hindelen and Lorentz method, the experimental data were approximated by theoretical crystalline, mesomorphous peaks and an amorphous halo as Gaussian and Lorentzian functions using the WAXS program. The shapes and $2 \theta$ position of the crystalline, amorphous peaks and the mesomorphous halo were selected according to Stoclet et al. [46,47].

The obtained X-ray diffractograms, which exhibit changes in the crystalline structure, are shown in figures 9 and 10. Table 7 presents the changes in the crystallinity level for the PLGA/1\%
Table 7. The crystallinity degree determined for the granulates and samples obtained by electrospinning from $15 \%$ solutions in DMSO with $1 \%$ HAp added.

\begin{tabular}{|c|c|}
\hline Polymer & Crystallinity degree (\%) \\
\hline PLGA granulate & 0 \\
\hline PLGA/1\% HAp & 4 \\
\hline PLGA/PHB granulate & 0 \\
\hline PLGA/PHB/1\% HAp & 3 \\
\hline
\end{tabular}

DMSO, dimethyl sulphoxide; HAp, hydroxyapatite; PHB, polyhydroxybutyrate; PLGA, poly(l-lactide-co-glicolide).

HAp and PLGA/PHB/1\% HA samples compared with those of the baseline polymer materials.

To assess the effect of sterilisation on the change of properties of the polymer materials used for the fabrication of nonwovens, a comparative analysis was conducted using GPC and ${ }^{1} \mathrm{H}$ NMR techniques. The results are presented in figure 11. 

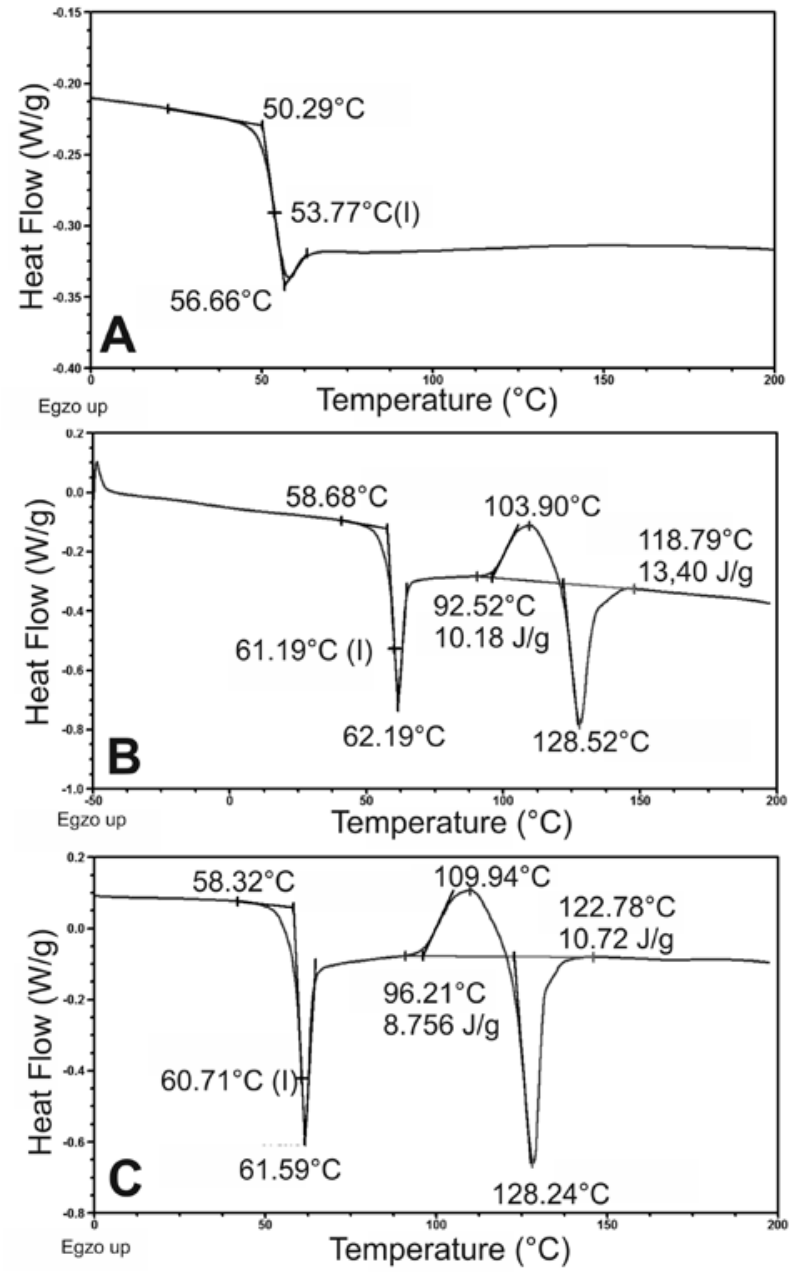

Figure 7. Differential scanning calorimeter (DSC) curves for the poly(Ilactide-co-glicolide) (PLGA) polymer (a) and the PLGA fibres formed by electrospinning with $1 \%$ hydroxyapatite (HAp) added, before sterilisation (b) and after sterilisation (c)
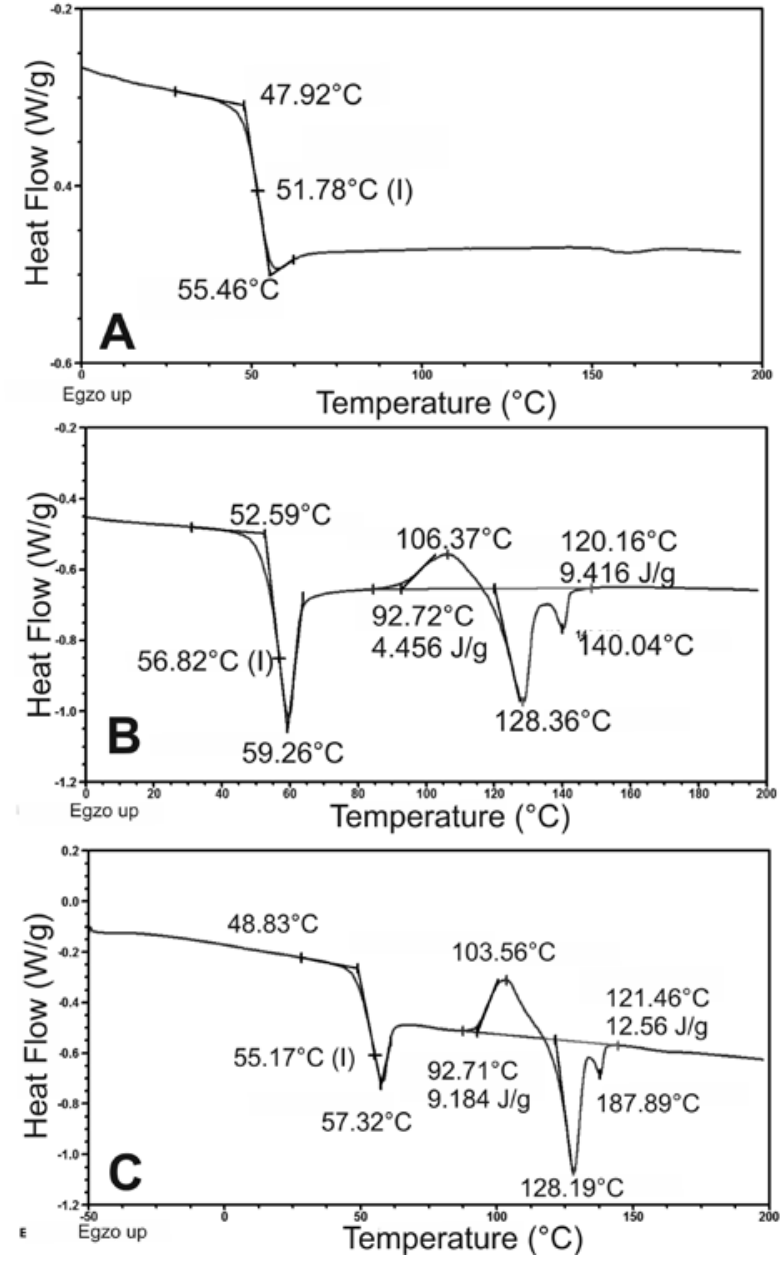

Figure 8. Differential scanning calorimeter (DSC) curves for the poly(l-lactide-co-glicolide) (PLGA)/polyhydroxybutyrate (PHB) polymer (a) and the PLGA/PHB fibres formed by electrospinning with $1 \%$ hydroxyapatite (HAp) added, before sterilisation (b) and after sterilisation (c)

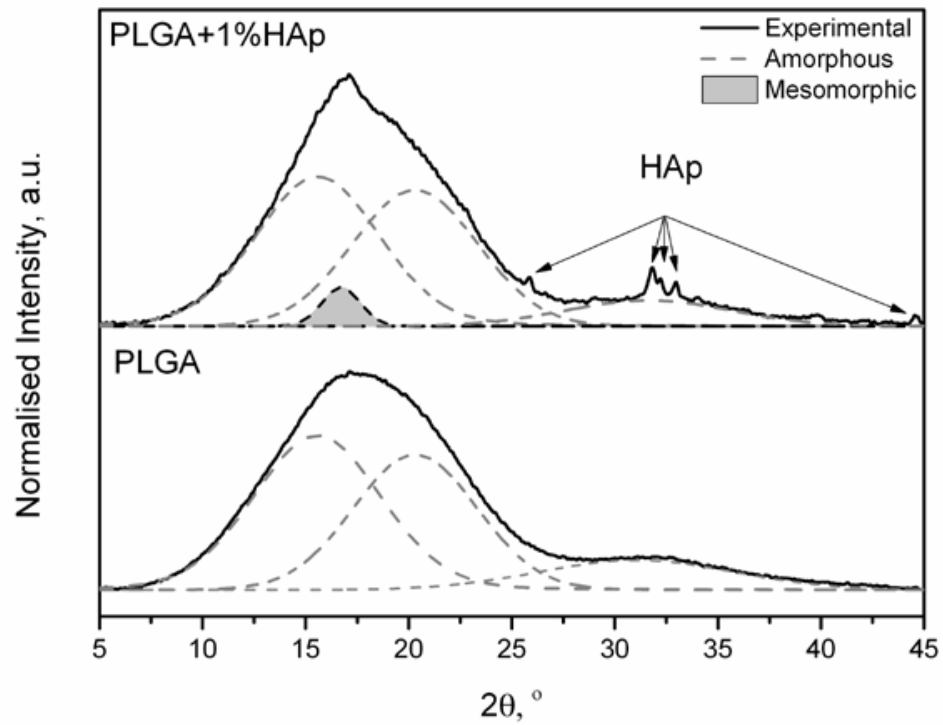

Figure 9. An X-ray diffractogram for the poly(I-lactide-co-glicolide) (PLGA) granulate (marked as PLGA) and for the sample electrospun from a $15 \%$ PLGA solution in dimethyl sulphoxide (DMSO) with a $1 \%$ hydroxyapatite (HAp) addition (marked as PLGA+1\% HAp) 


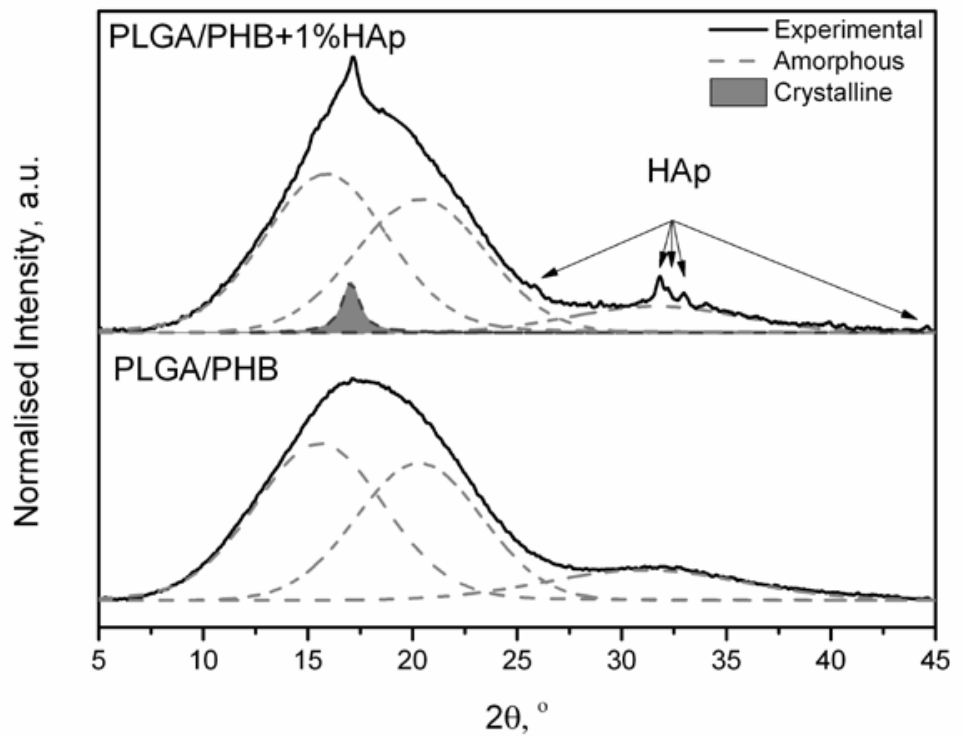

Figure 10. An X-ray diffractogram for the poly(I-lactide-co-glicolide) (PLGA)/polyhydroxybutyrate (PHB) granulate (marked as PLGA/PHB) and for the sample electrospun from the $15 \%$ PLGA/PHB solution in dimethyl sulphoxide (DMSO) with the $1 \%$ hydroxyapatite (HAp) addition (marked as PLGA/PHB+1\% HAp)

\section{Discussion of results}

The presented findings indicate that, in most cases, adding HAp to the spinning solutions resulted in an increase in the transverse dimensions of the fibres obtained from these solutions. Such a tendency was observed both for the PLGA polymer solution in DMSO with 1\% HAp added and for the PLGA/PHB blend solution in DMSO with the addition of $1 \%$ HAp. For the PLGA copolymer solution in DMSO, fibres with diameters ranging from 90 to $1060 \mathrm{~nm}$, depending on the fabrication conditions, were obtained. For the PLGA copolymer solution in DMSO with 1\% HAp, nonwovens characterised by average transverse fibre diameters ranging from 280 to $460 \mathrm{~nm}$ were obtained. However, the fibres obtained from PLGA solutions containing HAp were characterised by more significant dispersion of the transverse dimensions than those obtained from PLGA solutions with HAp added. The variance coefficient for HAp-free PLGA nonwovens ranged from $29.59 \%$ to $95.13 \%$, depending on the polymer concentration in the solution, and that for PLGA nonwovens with HAp ranged from $22.17 \%$ to $50.79 \%$, as presented in figures 1,2 and 4 .

The results of electrospinning from the PLGA/PHB solution with and without $\mathrm{HAp}$ failed to indicate any effect of the nanoadditive on the transverse dimensions of the obtained fibres. For the PLGA/PHB blend solutions in DMSO without HAp, transverse fibre dimensions ranging from 190 to $310 \mathrm{~nm}$, depending on the polymer concentration in the spinning solution, were obtained, whereas for the PLGA/PHB solutions in DMSO containing $\mathrm{HAp}$, the transverse fibre dimensions ranged from 80 to $350 \mathrm{~nm}$ and also depended on the polymer concentration in the spinning solution. However, a decrease of the variance coefficient value for the transverse diameter due to the HAp addition was observed. The variance coefficient obtained for PLGA/PHB solutions in DMSO with and without the 1\% HAp addition ranged from $27.77 \%$ to $64.05 \%$ and from $25.56 \%$ to $43.69 \%$, respectively. The transverse dimensions for samples
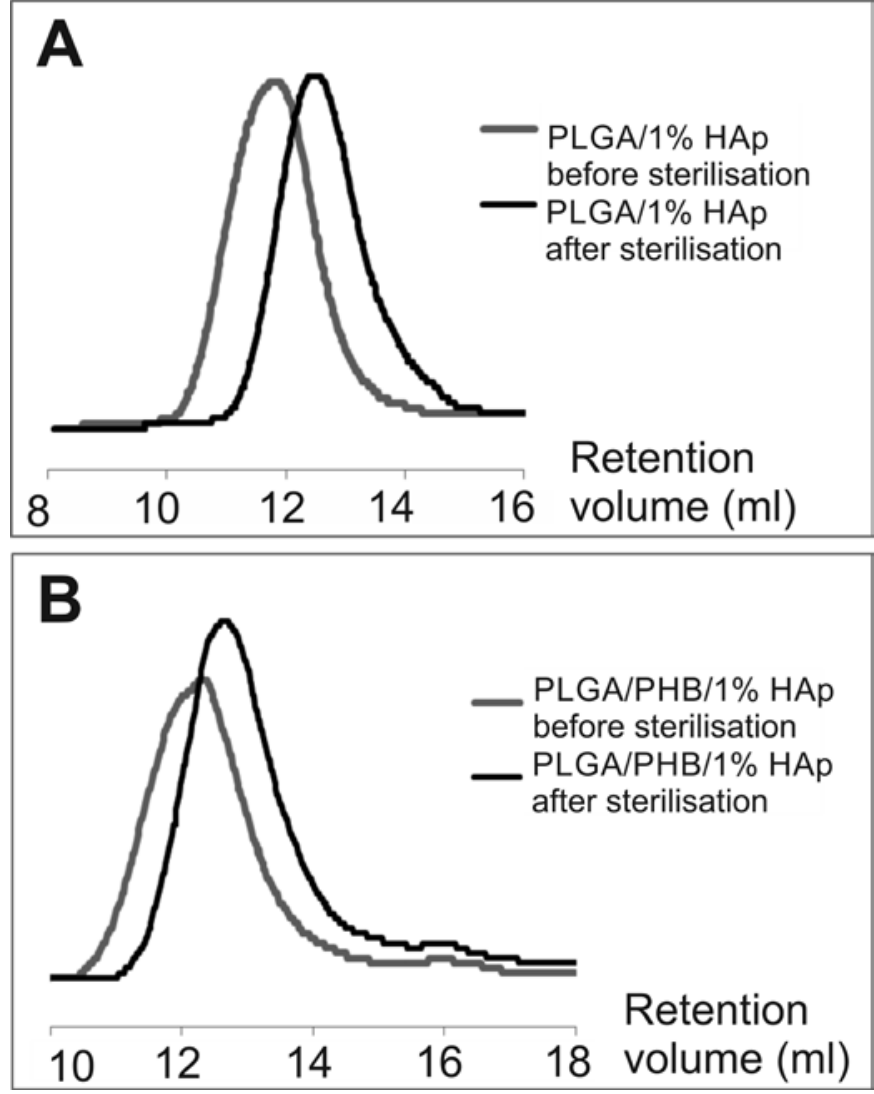

Figure 11. The elution curves before and after sterilisation for (a) the poly(I-lactide-co-glicolide) (PLGA)/1\% hydroxyapatite (HAp) copolymer and (b) the PLGA/polyhydroxybutyrate (PHB)/1\% HAp polymer blend

with and without the HAp addition are presented in figures 5 and 6 , respectively.

The effect of the PLGA concentration in the spinning solution on the transverse dimensions of the obtained fibres was also investigated. As the polymer concentration in the solution 
increased, the transverse dimension of the fibre decreased; however, the variation coefficient increased. This result implies that the PLGA concentration in the solution affected the stability of the electrospinning process; therefore, the $6 \%$ concentration of PLGA in DMSO was determined to be optimal. The transverse dimension of the fibres formed from the 6\% PLGA solution in DMSO under optimal conditions with a $30 \mathrm{kV}$ voltage and a 25 $\mathrm{cm}$ distance between the electrodes was approximately 0.34 $\mu \mathrm{m}$, with a variation coefficient level of $29.59 \%$.

An opposite correlation, i.e., the fibre diameter, increased and the variation coefficient decreased due to an increase in the polymer concentration in the spinning solution, was observed for the PLGA solutions in DMSO with HAp added. The polymer concentration of $15 \%$ was determined to be optimal. The transverse dimension of the fibres formed from the 15\% PLGA solution in DMSO with HAp under the specified electrospinning conditions was $0.46 \mu \mathrm{m}$, with a variation coefficient level of $22.17 \%$.

The analysis of the effect of the PLGA/PHB concentration on the transverse dimensions of the obtained fibres indicated that an increase in the polymer concentration in the solution resulted in increased transverse fibre dimensions and an increase of the variation coefficient value, irrespective of the presence of the nanoadditive in the spinning solution. The concentration of $15 \%$ was regarded as optimal. The transverse dimension of the fibres obtained from the 15\% PLGA/PHB solution in DMSO was $0.19 \mu \mathrm{m}$, with a variation coefficient of $27.77 \%$. The $15 \%$ concentration was also determined to be optimal for the PLGA/ $\mathrm{PHB}$ solution in DMSO with $1 \% \mathrm{HAp}$. The transverse dimension of the fibres obtained from that solution was $0.18 \mu \mathrm{m}$, with a $25.56 \%$ variation coefficient level.

The nonwovens obtained from the 15\% PLGA solution in DMSO with the addition of $1 \% \mathrm{HAp}$ and those obtained from the $15 \%$ PLGA/PHB solution in DMSO with the addition of $1 \%$ HAp were selected for further analyses. The aforementioned samples were selected because of the stability of the spinning process, the obtained transverse dimensions of fibres and homogeneity.

The assessment of the macroscopic and functional properties of the nonwovens fabricated under conditions regarded as optimal demonstrated that the transverse dimension of the fibre affected the total pore area and the dimension of the pores in the material. The nonwoven obtained from PLGA/PHB/1\% HAp, whose fibres are thinner, is characterised by smaller pores than the nonwoven obtained from PLGA/1\% HAp. Thus, the fibre thickness and pore dimensions affected the resultant air permeability. Because the PLGA/PHB/1\% HAp nonwoven pores are smaller than those of the PLGA/1\% HAp nonwoven, the obtained air permeability was also considerably lower for the former material. The pore dimension and total pore area results are presented in table 4 , and the air permeability results are presented in table 5 .

The assessment of mechanical properties indicates that the PLGA/1\% HAp nonwoven is characterised by a higher elongation at break than the PLGA/PHB/1\% HAp nonwoven.
The elongation at break value for the PLGA nonwoven is nearly 6 -fold higher than that for the PLGA/PHB/1\% HAp nonwoven for tests performed in the longitudinal direction and nearly 10fold higher for tests performed in the transverse direction.

The statistical analysis demonstrates that the radiation sterilisation process also exerted an effect on the elongation at break. The nonwoven obtained from PLGA/1\% HAp was stiffer after sterilisation, and its elongation at break tested in both directions decreased by $38 \%$ in the longitudinal and by $55.5 \%$ in the transverse direction. The observed changes were statistically significant. A significant decrease of the elongation at break in both the longitudinal and transverse directions was also observed for the nonwovens obtained from PLGA/ $\mathrm{PHB} / 1 \% \mathrm{HAp}$ after sterilisation. The changes after sterylisation after sterilisation reached approximately $32 \%$.

The effect of radiation sterilisation on the values of stress at break was also analysed for the selected samples. The stress at break value tested in the longitudinal direction after sterilisation decreased by $14 \%$ for the PLGA $/ 1 \%$ HAp sample. Such a difference in results before and after sterilisation was statistically significant. The decrease of the stress at break value tested in the transverse direction for the PLGA sample was also statistically significant and reached approximately $23 \%$.

A decrease of the values of stress at break was also observed for the PLGA/PHB/1\% HAp nonwoven after sterilisation. In the tests conducted in both directions, the stress at break value decreased by approximately $13 \%$, which was statistically significant. The mechanical property results are presented in table 6 .

A comparative assessment of the DSC thermograms obtained for the baseline polymer granulate and the selected nonwoven products before and after sterilisation was conducted to assess their thermal properties as well as the changes resulting from processing of the polymer and the applied sterilisation.

The thermogram obtained for the baseline PLGA granulate only exhibits a peak responsible for the vitrification temperature. This finding indicates that the analysed material granulate was completely amorphous in character and was characterised by a glass transition temperature of approximately $54^{\circ} \mathrm{C}$. When comparing the glass transition temperature for the initial granulate sample and the sample electrospun from PLGA $1 \%$ $\mathrm{HAp}$, a shift of the peak value towards a higher temperature, reaching $61^{\circ} \mathrm{C}$, is evident. No changes in the glass transition temperature for the electrospun samples before and after sterilisation were observed. The samples obtained by electrospinning before and after sterilisation also exhibit melting and recrystallisation peaks. This finding indicates that the sample underwent a process leading to the formation of a more ordered structure and crystallites. The maximum temperature values for such transformations were not affected by the sample sterilisation.

The same phenomena were observed for the PLGA/ PHB samples. The thermogram for the baseline PLGA/ 
PHB granulate only exhibits a peak responsible for the glass transition temperature at approximately $52^{\circ} \mathrm{C}$. For the samples after PLGA/PHB/1\% HAp electrospinning, before and after sterilisation, a shift of the peak value towards a higher temperature of approximately $57^{\circ} \mathrm{C}$ is also visible. Thus, the effect of radiation sterilisation on the glass transition temperature was negligible. Melting and recrystallisation peaks were also observed, similar to those observed for PLGA/1\% HAp. Likewise, the maximum temperature values for such transformations were not affected by sample sterilisation.

The WAXS analyses indicate that only the amorphous phase is visible in the diffractograms obtained for the baseline PLGA polymer and PLGA/PHB blend granulates. The PLGA and PLGA/PHB granulates are 100\% amorphous. However, the electrospinning process resulted in ordering of the supramolecular structure. The X-ray diffractograms for the obtained nonwovens reveal mesomorphous peaks for the sample obtained by PLGA $1 \%$ HAp electrospinning and crystalline peaks for the sample obtained by PLGA/PHB/1\% HAp electrospinning. The crystallinity level of the PLGA-based sample increased to $4 \%$ and that of the PLGA/PHB-based sample increased to $3 \%$. The crystallinity level results are presented in table 7 .

The effect of radiation sterilisation on nonwoven materials electrospun from PLGA/1\% HAp and PLGA/PHB/1\% HAp blend was also investigated using comparative GPC and ${ }^{1} \mathrm{H}$ NMR analysis. A marked decrease of the average molar mass was observed with preserved unimodal character, both for the copolymer and the polymer blend. No changes in either copolymer or polymer blend composition were observed based on determinations performed using the ${ }^{1} \mathrm{H}$ NMR technique.

\section{Conclusions}

1. The technological parameters of electrospinning and polymer concentration in the spinning solution exerted a considerable effect on the transverse dimensions of the obtained fibres:

- Increasing the polymer concentration in the spinning solution for the PLGA/PHB system, with or without HAp added, as well as for the PLGA system with $1 \% \mathrm{HAp}$, resulted in an increase of the average fibre diameter. However, for the PLGA system without HAp added, an increase of the polymer concentration in the solution resulted in a decrease in the fibre transverse dimensions.

- The technological parameters of electrospinning, such as the applied voltage and the distance between the upper and lower electrodes, also affected the transverse dimensions of the fibres. Increased values of these parameters were correlated with decreased transverse dimensions of the obtained fibres. In addition, increasing the voltage applied to the electrodes resulted in reduced dispersion of the transverse dimensions of the analysed fibres in the formed nonwoven material, and increasing the distance between the electrodes resulted in the opposite tendency, i.e., increased dispersion of the transverse dimensions of the fibres. Therefore, a voltage of $30 \mathrm{kV}$ and a 25 $\mathrm{cm}$ distance between the electrodes were determined to be the optimal parameters for the electrospinning process. Increased transverse diameters of the fibres were also correlated with the addition of HAp to the spinning solution. A two-fold increase in transverse dimensions was observed for the fibres obtained from the PLGA copolymer solution in DMSO with 1\% HAp added compared with the nonwovens fabricated from the PLGA solution without HAp content. In contrast, no effect of the HAp addition on the fibre transverse dimensions was observed for nonwovens obtained from the PLGA/PHB solution.

2. Considering the stability of the spinning process, as well as the transverse dimension and its homogeneity, it should be assumed that the optimal spinning conditions were obtained with a $30 \mathrm{kV}$ voltage applied to the upper electrode, a $25 \mathrm{~cm}$ distance between the electrodes, a $20 \mathrm{rpm}$ drum collector rotation speed and a $0.9 \mathrm{~mm}$ capillary diameter.

3. The thermograms for the PLGA copolymer granulates and PLGA/PHB blends exhibit only the $\mathrm{T}_{g}$ temperature, whereas the thermograms for the nonwovens obtained by electrospinning from the PLGA copolymer and the PLGA/PHB blends with the HAp addition exhibit additional peaks corresponding to the cold crystallisation temperature $\left(T_{c}\right)$ and the $T_{m}$ temperature. The aforementioned phenomenon is most likely associated with a more ordered polymer structure.

4. The GPC analysis indicates that the sterilisation process of the nonwovens obtained from PLGA/1\% HAp and PLGA/ $\mathrm{PHB} / 1 \% \mathrm{HAp}$ resulted in a significant decrease of the average molar mass. The sterilisation process also affected the values of the mechanical strength parameters. Sterilisation caused a decrease of stress and elongation at break.

\section{Acknowledgements}

This research was financed within the framework of the BIOGRATEX Project „Biodegradable fibrous products,” UDAPOIG.01.03.01-00-007/08-00.

The authors would like to express their sincere thanks to: Agnieszka Komisarczyk, Ph.D. (Eng.) for conducting the porosity tests, Michał Chrzanowski, Ph.D. (Eng.) for the DSC analyses and Michał Puchalski, Ph.D. (Eng.) for the WAXS analyses.

\section{References}

[1] Pamuła, E., (2008). Biomateriały dla inżynierii tkankowej. Badania nad kształtowaniem struktury $i$ właściwości biologicznych poliestrów alifatycznych. Prace monograficzne AGH Kraków, Wydział Inżynierii Materiałowej i Ceramiki, (Cracow), 1

[2] Ashammakhi, N., Mäkelä, E.A., Törmälä, P., Waris, T., Rokkanen, P., (2000). Effect of self-reinforced polyglycolide membrane on osteogenesis: an experimental study in rats. Plast. Surg., 23, 423-428

[3] He, L., Liao, S., Quan, D., Ngiam, M., Chan, C.K., Ramakrishna, S., Lu, J., (2009). The influence of lamininderived peptides conjugated to Lys-capped PLLA on 
neonatal mouse cerebellum C17.2 stem cells. Biomaterials, 30, 1578-1586

[4] Keskin, D.S., Tezcaner, A., Korkusuz, P., Korkusuz, F., Hasirci, V., (2005). Collagen-chondrotin sulfate-based PLLA-SAIB-coated rhBMP-2 delivery system for bone repair Biomaterials, 26, 4023-4034

[5] Shikinami, Y., Matsusue, Y., Nakamura, T., (2005). The complete process of bioresorption and bone replacement using devices made of forged composites of raw hydroxyapatite particles/poly l-lactide (F-u-HA/PLLA). Biomaterials, 26, 5542-5551

[6] LeGeros, R.Z., Lin, S., Rohanizadeh, R., Mijares, D., LeGeros, J.P., (2003). Biphasic calcium phosphate bioceramics: preparation, properties and applications, J. Mater. Med., 14, 201-209

[7] Orlovskii, V.P., Komlev, V.S., Barinov, S.M., (2002). Hydroxyapatite-Based Ceramics. Inorganic Materials, 10 , 973-984

[8] Ślósarczyk, A., Stobierska, E., Paszkiewicz, Z., Gawlicki, M., (1996). Calcium phosphate materials prepared from precipitates with various calcium: phosphorous molar ratios. J. Am. Ceram. Soc., 79, 2539-2544

[9] Ślósarczyk, A., Piekarczyk, J., (1999). Ceramic materials on the basis of hydroxyapatite and tricalcium phosphate. Ceramics Int. 25, 561-565

[10] Yoshikawa, H., Myoui, A., (2005). Bone tissue engineering with porous hydroxyapatite ceramics J. Art. Organs, 8, 131-136

[11] Nie, X., Leyland, A., Matthews, A., (2000). Deposition of layered bioceramic hydroxyapatite/TiO2 coatings on titanium alloys using and electrophoresis. Surf. Coat. Tech. 125, 407-414

[12] Noh, H.K., Lee, S.W., Kim, J.-M., Oh, J.-E., Kim, K.-H., Chung, Ch.-P., Choi, S.-Ch., Park, W.H., Min, B.-M., (2006). Electrospinning of chitin nanofibers: Degradation behavior and cellular response to normal human keratinocytes and fibroblasts. Biomaterials, 27, 3934-3944

[13] Ramesh, S., Tan, C.Y., Peralta, C.L., Teng, W.D., (2007). The effect of manganese oxide on the sinterability of hydroxyapatite. Sci. Technol. Adv. Mater., 8, 257-263

[14] Søballe, K., (1993). Hydroxyapatite ceramic coating for bone implant fixation: Mechanical and histological studies in dogs. Acta Orthopead. 64, 1-58

[15] Vallet-Regi, M., Gonzalez-Calbet, J.M., (2004). Calcium phosphates as substitution of bone tissues. Prog. Solid State Ch. 32, 1-31

[16] Illić, V., Šaponjić, Z., Vodnik, V., Potkonjak, B., Jovančić, P., Nedeljković, J., Radetić, M., (2009). The influence of silver content on antimicrobial activity and color of cotton fabrics functionalized with $\mathrm{Ag}$ nanoparticles. Carbohyd. Polym. 78, 564-569

[17] Yates, C.C., Whaley, D., Babu, R., Zhang, J., Krishna, P., Beckman, E., Pasculle, A.W., Wells A., (2007). The effect of multifunctional polymer-based gels on wound healing in full thickness bacteria-contaminated mouse skin wound model. Biomaterials, 28, 3977-3986

[18] Brammer, K.S., Oh, S., Cobb, Ch.J., Bjursten, L.M., van der Heyde, H., Jin, S., (2009). Improved bone-forming functionality on diameter-controlled $\mathrm{TiO} 2$ nanotube surface. Acta Biomat. 5, 3215-3223

[19] Lübbe, A.S., Alexiou, Ch., Bergemann, Ch., (2001). Clinical Applications of Magnetic Drug Targeting. J. Surg. Res., 95, 200-206
[20] Jordan, A., Scholz, R., Maier-Hauff, K., Johannsen, M., Wust, P., Nadobny, J., Schirra, H., Schmidt, H., Deger, S., Loening, S., Lanksch, W., Felix, R., (2001) Presentation of a new magnetic field therapy system for the treatment of human solid tumors with magnetic fluid hyperthermia. J. Magn. Magn. Mater. 225, 118-126

[21] Maier-Hauff, K., Rothe, R., Scholz, R., Gneveckow, U., Wus,t P., Thiesen, B., Feussner, A., von Deimling, A., Waldoefner, N., Felix, R., Jordan, A.,(2007). Intracranial Thermotherapy using Magnetic Nanoparticles Combined with External Beam Radiotherapy: Results of a Feasibility Study on Patients with Glioblastoma Multiforme. J. NeuroOncol. 81, 53-60

[22] Kong, Y.-M., Bae, Ch.-J., Lee, S.-H., Kim, H.-W., Kim, H.E., (2005). Improvement in biocompatibility of ZrO2-Al2O3 nano- composite by addition of HA, Biomaterials, 26, 509517

[23] Peltola, T., Jokinen, M., Veittola, S., Rahiala, H., Yli-Urpo, A., (2001). Influence of sol and stage of spinnability on in vitro bioactivity and dissolution of sol-gel-derived $\mathrm{SiO} 2$ fibers Biomaterials, 22, 589-598

[24] Huang, Z.-M., Zhang, Y.-Z., Kotaki, M., Ramakrishna, S., (2003). A review on polymer nanofibers by electrospinning and their applications in nanocomposites. Comp. Sci. Techn., 63, 2223-2253

[25] Vollath, D., (2008). Nanomaterials: An Introduction to Synthesis. Properties and Applications, Wiley-VCH Verlag GmbH\&Co. KGaA, (Weinheim)

[26] Burger, C., Hsiao, B.S., Chu, B., (2006). Nanofibrous materials and their applications, Annu. Rev. Mater. Res., 36, 333-368

[27] lonescu, L.C., Lee, G. C., Sennett, B.J., Burdick, J.A., Mauck, R.L., (2010). An anisotropic nanofiber/microsphere composite with controlled release of biomolecules for fibrous tissue engineering. Biomaterials, 31, 4113-4120

[28] Liu, W., Thomopoulos, S., Xia, Y., (2012). Electrospun Nanofibers for Regenerative Medicine. Adv. Healthcare Mater. 1, 10-25

[29] Lim, L.-T., Auras, R., Rubino, M., (2008). Processing technologies for poly(lactic acid). Prog. Polym. Sci., 33, 820-852

[30] Pillai, C.K.S., Sharma, C.P., (2009). Electrospinning of Chitin and Chitosan Nanofibres. Trends Biomater. Artif. Organs, 22, 179-201

[31] Ito, Y., Hasuda, H., Kamitakahara, M., Ohtsuki, Ch., Tanihara, M., Kang, I.-K., Kwon, O.H., (2005). A composite of hydroxyapatite with electrospun biodegradable nanofibres as a tissue engineering material. J. Biosci. Bioeng. 100, 43-49

[32] Li, Ch., Jin, H.-J., Botsaris, G.D., Kaplan, D.L., (2005). Silk apatite composites from electrospun fibres. J. Mater. Res. 20, 3374-3384

[33] Shin, H.J., Lee, Ch.H., Cho, I.H., Kim, Y.-J., Lee, Y.J., Kim, I.A., Park K.-D., Yui N., Shin J.-W., (2006). Electrospun PLGA nanofiber scaffolds for articular cartilage reconstruction: mechanical stability, degradation and cellular responses under mechanical stimulation in vitro. J. Biomater. Sci. Polym. Ed., 17, 103-119

[34] Subramanian, A., Vu, D., Larsen, G.F., Lin, H.-Y., (2005). Preparation and evaluation of the electrospun chitosan/ $P E O$ fibers for potential applications in cartilage tissue engineering. J. Biomater. Sci. Polym. Ed. 16, 861-873 
[35] Riboldi, S.A., Sampaolesi, M., Neuenschwander, P., Cossu, G., Mantero, S., (2005). Electrospun degradable polyesterurethane membranes: potential scaffolds for skeletal muscle tissue engineering. Biomaterials, 26, 4606-4615

[36] Sahoo, S., Ouyang, H., Goh, C.-H.J., Goh, Tay, T.E., Toh, S.L., (2006). Characterization of a Novel Polymeric Scaffold for Potential Application in Tendon/Ligament Tissue Engineeing, Tissue Eng. 12, 91-99

[37] Jeong, L., Yeo, I.-S., Kim, H.N., Yoon, Y., Jang, D.H., Jung, S.Y., Min, B.-M., Park, W.H., (2009). Plasma-treated silk fibroin nanofibers for skin regeneration. Int. J. Biolog. Macromol. 44, 222-228

[38] Dobrzyński, P., Kasperczyk, J., Janeczek, H., Bero, M., (2001). Synthesis of Biodegradable Copolymers with the Use of Low Toxic Zirconium Compounds. 1. Copolymerization of Glycolide with L-Lactide Initiated by $\mathrm{Zr}$ (Acac)4. Macromolecules, 34 (15), 5090-5098

[39] Adamus, G., Kowalczuk, M., (2008). Anionic Ring-Opening Polymerization of -Alkoxymethyl-Substituted-Lactones. Biomacromolecules, 9, 696-703
[40] Patent Nr EP 2325355 B1 nt.: System for electrospinning of fibers, Twórcy: Krucińska I., Gliścińska E., Chrzanowski M.

[41] ISO 9073-1:1989 standard, Methods of test fornonwovens. Determination of mass per unit area

[42] ISO 9073-2:1995 standard Methods of test for nonwovens. Determination of thickness

[43] PN EN ISO 9073-15:2009standardTextiles. Test methods for nonwovens. Determination of air permeability

[44] EN ISO 29073-3:1992 standard, Methods of test for nonwovens. Determination of tensile strength and elongation

[45] Guide to Expression of Uncertainty in Measurement, (1999). GUM, (Warszawa)

[46] Puchalski, M., Krucinska, I., Sulak, K., Chrzanowski, M., Wrzosek, H., (2013). Influence of the calender temperature on the crystallization behaviors of polylactide spunbonded non-woven fabrics. Textile Research Journal, DOI:10.1177/0040517513478480

[47] Stoclet, G., Seguela, R., Lefebvre, J-M., (2010). New insights on the strain-induced mesophase of poly $(D, L-$ lactide): in situ WAXS and DSC study of thermo-mechanical stability. Macromolecules, 43, 7228-7237 